\title{
Molecular characterization of chromosome 7 in AML and MDS patients
}

\author{
Heba N. Abdelrazik*, Hala M. Farawila, Mai A Sherif, Mervat AlAnsary \\ Clinical Pathology Department, Faculty of Medicine Cairo University \\ 14 Aly El Gendy, 6th district Nasr City, Cairo, Egypt
}

*Author for Correspondence: . E-mail: hebanabil@gmail.com

\begin{abstract}
SUMMARY
Myelodysplastic syndromes (MDS) share many features with acute myeloid leukemias (AML) and in fact $20-\mathbf{4 0 \%}$ of the patients eventually develop a picture of full blown AML. Chromosome 7 has been a focus of attention as a site harboring tumor suppressor genes whose loss of function contributes to leukemia transformation or tumor progression. Abnormalities of chromosome 7 are frequently encountered in AML and MDS. The aim of the present study was to detect the molecular abnormalities of chromosome 7 in Egyptian AML and MDS patients using the FISH technique and whether the abnormality has an implication on the prognosis of the disease after a period of one year follow up. Fluorescence in-situ hybridization (FISH) was performed for chromosome 7 using a locus specific probe for 7q31 and a centromeric probe from 7p11.1-q11.1 in a series of 30 patients diagnosed as: AML (20 patients) and MDS (10 patients) according to the FAB criteria. Aberrations of Chromosome 7 were found in 36.6\% of AML patients: 3 cases showing monosomy with a mean positivity of $17.3 \%, 2$ cases showing $7 q$ deletion with a mean positivity of $11 \%$. While both monosomy and deletion were detected in 3 cases. However, in MDS patients; monosomy for chromosome 7 was the only abnormality detected and was found in $30 \%$ of cases. Genetic abnormality of chromosome 7 showed a significant association with poor prognostic criteria. Patients who had normal FISH results showed a higher percentage $\mathbf{3 1 . 6 \%}$ ) of complete remission (CR) versus $0 \%$ in patients with monosomy or deletion who showed a higher percentage $(100 \%)$ of death or poor response to therapy (NR). Although AML patients had a worse prognosis when compared to MDS patients, patients with genetic abnormalities showed the worst outcome.
\end{abstract}

[Afr J Health Sci. 2006;13:33-42]

\section{Introduction}

The long arm of human chromosome 7 between $7 \mathrm{q} 22$ and $7 \mathrm{q} 36$ has been identified as a region harboring one or more tumor-suppressor genes (TSGs) inactivated in acute myeloid leukemia (AML) [1]. Allelotyping studies have delineated at least three distinct loci that are frequently deleted [2, 3]: 7q22, 7q31.1, and 7q31.3. Among these, a correlation between survival and deletion limits implicates loss in the cytogenetic bands $7 \mathrm{q} 31 \sim \mathrm{q} 32$ in refractoriness to therapy $[4,5]$.

Complete and interstitial losses of chromosome 7 (-7, 7q-) are nonrandom anomalies seen in de novo and therapy-induced myeloid neoplasms as well as leukemias arising from occupational or environmental exposure to mutagens. Monosomy 7 in adult myeloid neoplasms, is more common than the interstitial deletions of the long arm (7q-). The importance of monosomy 7 is evident from the small but significant number of adult acute myeloid leukemia (AML) cases in which it occurs as the sole anomaly [6]. Childhood monosomy 7 seen secondary to
Fanconi's anemia, juvenile chronic myeloid leukemia, Down's syndrome as well as familial monosomy 7 may share genetic alterations associated with adult myeloid neoplasms [7]. The poor prognosis associated with chromosome 7 anomalies in adult myelodysplasia (MDS) and AML underscores the need for molecular analysis $[8,9]$.

Interstitial deletions of $7 q$, seen in a variety of solid tumors with distinct segments of loss at bands $7 q 11,7 q 22$, and 7q31 that are apparently unique to specific neoplasms, have raised the possibility of a number of tumor suppressor genes in the long arm of chromosome 7 [10]. In the past, delineation of the critical regions of loss in $7 q$ has been the focus of several investigations on solid tumors as well as hematopoietic neoplasms [11-13]. Fluorescence in situ hybridization analyses have delineated a critical region of loss at $7 q 22$ in myeloid malignancies [14]. Other studies have raised the possibility of unbalanced translocations of fragments of chromosome 7 being located on 
marker chromosomes; patients who were perceived to be monosomic by centromere-specific probes showed strong hybridizations to marker chromosomes with chromosome 7-painting probes [15]. However, the extent and variability of $7 \mathrm{q}$ deletions have so far prevented the identification of a putative tumor suppressor gene. The molecular mechanisms underlying these chromosomal abnormalities also remain unclear. Other investigators have identified a number of sequence elements/motifs that are frequently present near the breakpoints of chromosomal rearrangements and may suggest how these rearrangements occurred. They include Alu repeats, chi-like sequences, DNA topoisomerase II consensus binding sites and sequences with homology to the heptamer and nanomer motifs of the $\mathrm{V}(\mathrm{D}) \mathrm{J}$ recognition signal sequence [16]. Accordingly, the present study aimed to detect monosomy 7and 7q31 deletions among AML and MDS patients using FISH probes and to correlate whether the abnormality has an implication on the prognosis or response to therapy.

\section{Materials and Methods \\ Patients}

Forty samples were included in this study. Twenty

AML and Ten MDS patients who were newly diagnosed in Al Kasr El-Aini Hospital over a period of 2 years from January 2002 to January 2004 were enrolled in this study. Their ages ranged from 20-65 years with a mean of 41 years and the male to female ratio was 1.1. The diagnosis and sub classification of MDS and AML was based on morphological and cytochemical studies of peripheral blood (PB) smears, bone marrow (BM) aspirates, and biopsy specimens obtained before therapy, and immunophenotyping (Table 1)according to the French-American-British Cooperative Group criteria [17,18]. Ten age matched controls were involved to normalize FISH results. Complete hemogram and biochemical tests were done to the control group before the FISH analysis which was done on PB samples.

\section{Immunophenotyping}

10ul EDTA blood from each case was mixed with a panel of monoclonals; CD45,34,13,14,33\&38 (all purchased from Becton-Dickinson) after RBC's lysis and processed according to the manufacturer's guide. Analysis was performed on FACScan (Becton-Dickinson), lymphocytes or blasts were gated on a forward and side scatter profiles ( $>20 \%$ positivity were considered positive) [19].

Table 1: FAB subtypes of the studied groups

\begin{tabular}{||l||l|l||}
\hline FAB subtype & No. of cases (30) & Frequency \\
\hline \hline M1 & $4 / 20$ & $20 \%$ \\
\hline M2 & $3 / 20$ & $15 \%$ \\
\hline M3 & $3 / 20$ & $15 \%$ \\
\hline M4 & $6 / 20$ & $30 \%$ \\
\hline M5 & $4 / 20$ & $20 \%$ \\
\hline RA & $7 / 10$ & $70 \%$ \\
\hline RAEB & $3 / 10$ & $30 \%$ \\
\hline
\end{tabular}

\section{Culture}

Fresh peripheral blood PB samples were obtained from the control group and fresh bone marrow samples were used for all 30 MDS and AML cases. Mononuclear cell layer was separated using ficol hypaque density gradient centrifugation from both PB and BM samples [20].

Mononuclear cells were cultured for $24 \mathrm{~h}$ (short-term cell culture) without PHA. Five milliliters of RPMI 1640 medium supplemented with $15 \%$ of fetal calf serum and $1 \%$ L-glutamine were added to each culture tube. The cell concentration in the medium was adjusted to
$1 \times 10^{6} / \mathrm{ml}$. Colcemid at a final concentration of 0.05 $\mu \mathrm{g} / \mathrm{ml}$ was added $60 \mathrm{~min}$ before harvesting. Cells were treated with $0.075 \mathrm{MKCl}$ hypotonic solution at $37^{\circ} \mathrm{C}$ for 15 min followed by three changes of 3:1 methanol:glacial acetic acid fixative solution. The cells were finally resuspended in this fixative solution. The cells suspended in fixative solution were spread on slides in a Thermotron (CDS-5) at $30^{\circ} \mathrm{C}$ and $40 \%$ of humidity. The slides were put in a 2x SSC ( $1 x$ SSC $=150 \mathrm{mM}$ sodium chloride and $15 \mathrm{mM}$ sodium citrate solution) bath at $37^{\circ} \mathrm{C}$ for 30 min and then dehydrated in $70 \%, 80 \%$ and $100 \%$ 
ethanol. After air-drying the slides, FISH procedures were performed [21].

\section{FISH}

FISH analysis was performed using the commercially available locus specific identifier, LSI D7S522 Spectrum Orange/ CEP 7 Spectrum Green Dual Colour probe which hybridizes to band 7q31 (Spectrum Orange LSI D7S522) and to the centromere band region 7p11.1-q11.1, locus D7Z1 (Spectrum Green CEP 7) of human chromosome 7 (Vysis, Downers Grove, IL USA) according to the manufacturer's instructions. Improvements were obtained by incubating bone marrow slides at room temperature overnight before digestion with proteinase $\mathrm{K}$ (stock solution $1 \mathrm{mg} / \mathrm{ml}$ ) for $6 \mathrm{~min}$ at $37^{\circ} \mathrm{C}$. After washing twice with phosphate buffer solution $1 \mathrm{x}$, slides were fixed in a $1 \%$ formaldehyde solution; they were then denatured in $70 \%$ deionized formamide/ $2 \mathrm{xSSC}$ solution for $5 \mathrm{~min}$ at $74^{\circ} \mathrm{C}$ then successively passed through $70 \%, 80 \%$ and $100 \%$ ethanol at $-20^{\circ} \mathrm{C}$. The probe was denatured at $74^{\circ} \mathrm{C}$ for $5 \mathrm{~min}$ and added onto the slide and then covered with a coverslip. Hybridization was performed overnight at $37^{\circ} \mathrm{C}$ in a humidified chamber. Post-hybridization washing was done in $4 \mathrm{xSSC} \mathrm{NP} 40$ for $2 \mathrm{~min}$ at $74^{\circ} \mathrm{C}$ first and then for $2 \mathrm{~min}$ at room temperature. Slides were counterstained and mounted with DAPI II.

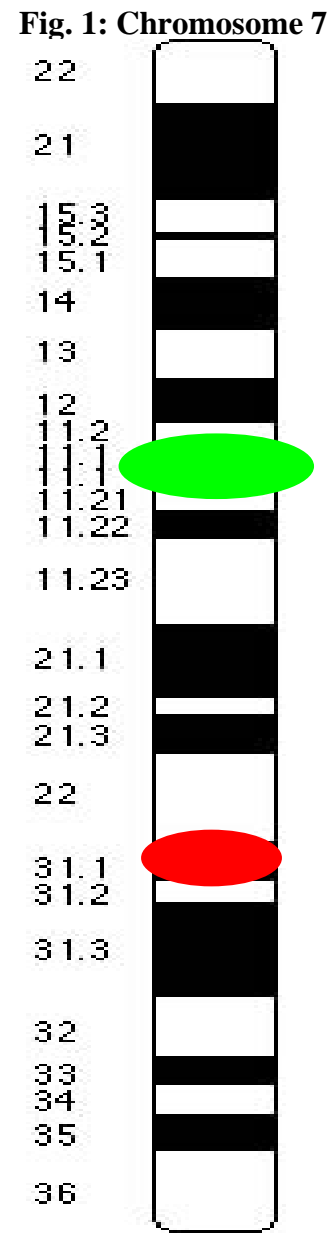

\section{Image analysis and scoring}

Images were viewed under the fluorescent microscope with the proper filter set: DAPI /orange/green were used to visualize the fluorescent signals. A total of 500 interphase and metaphase nuclei were analyzed using Vysis scoring criteria blindly scored by two individuals for each sample. The pictures were captured by using an Olympus BX60 microscope equipped with compulog IMAC-CCD S30 camera module and the insitu imaging system (ISIS 2) software version 2.5 (MetaSystem, Belmont, MA,USA). using x 100

objective lens. The centromere appeared as a green signal while $7 \mathrm{q} 31$ appeared as an orange signal. The number of fluorescent signals for each nucleus was noted as:

4 signals: 2 green and 2 orange were counted as a normal cell.

3 signals: 1 orange and 2 green indicated deletion $(7 \mathrm{q}-)$. 
2 signals: 1 green and 1 orange indicated monosomy 7 (-7).

0 (no signal could be seen): failure of hybridization, excluded Split signal: 2 signals with very short distance in-between were counted as 1 signal. Occasionally the probe may appear as five to six signals depending on the condensation of the
DNA and relative distance between chromatids. The signals may appear diffuse or split. In normal metaphase, LSI D7S522 may appear as 1 to 2 signals on each chromosome 7. Normal control specimens were incorporated and the cut off level was evaluated at $5 \%[22,23]$.

\section{Results}

Fig 2: FISH for chromosome 7 showing four signals of 3 interphase nuclei (normal): 2 green signals (internal control) representing the centromere of chromosome 7 and 2 red signals representing 7q31region

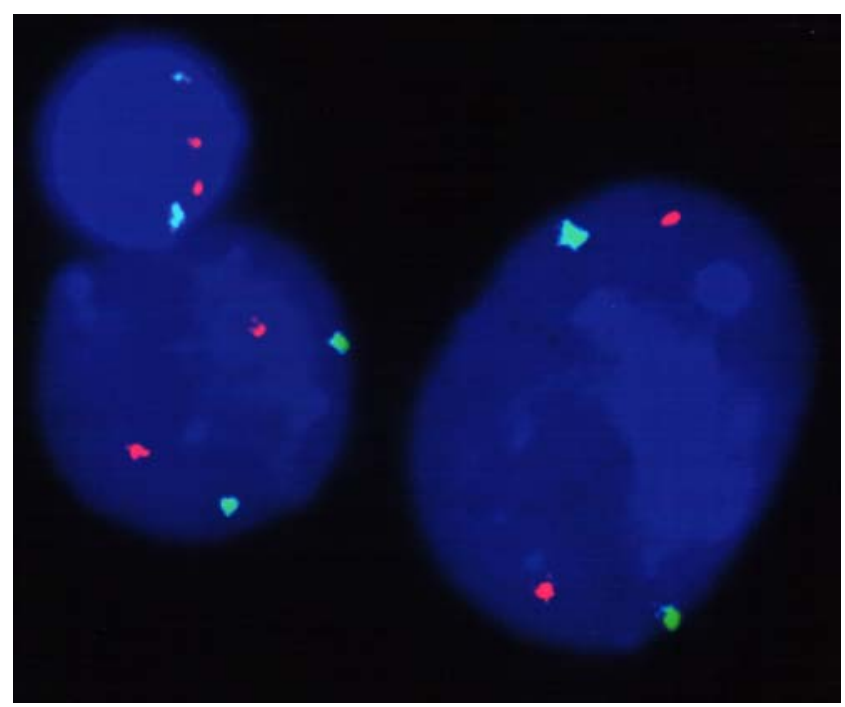

Fig 3: FISH for chromosome 7 showing four signals of a metaphase nucleus (normal): 2 green signals (internal control) representing the centromere of chromosome 7 and 2 red signals representing $7 q 31$ in both metaphase and interphase

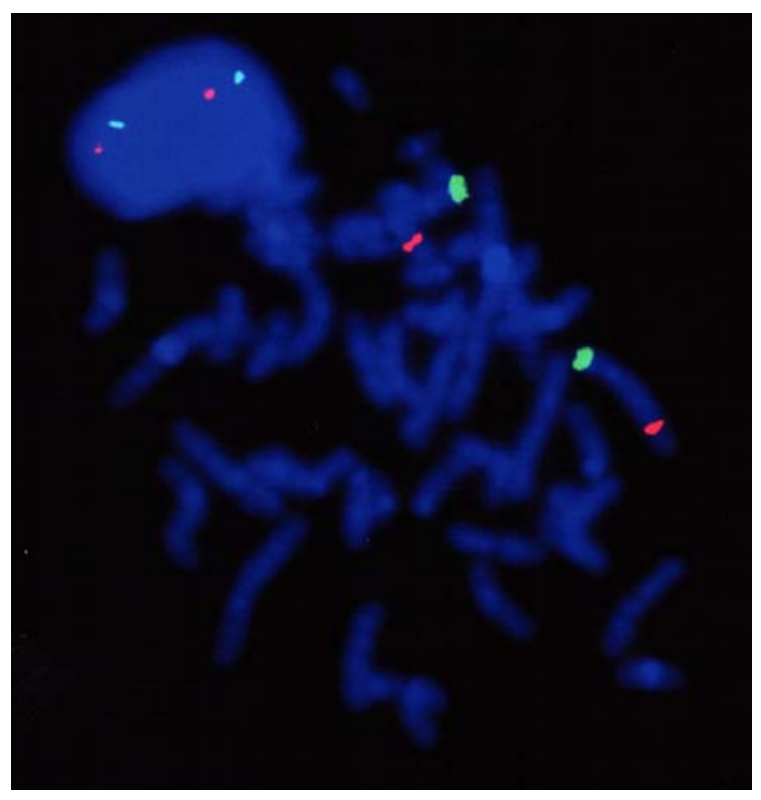


The 40 cases were classified into 3 groups: Group A; 20 AML patients, Group B; 10 MDS patients (Table 1) and Group C; 10 normal age-matched controls.

\section{Cytogenetic studies}

Chromosome 7 abnormalities were detected in $36.6 \%(11 / 30)$ of the patients. Eight patients were
AML and 3 patients were diagnosed as MDS, Table 2 summarizes the type of abnormality detected in each group.

Table 2: Frequency of chromosome 7 abnormalities in the study group

\begin{tabular}{||l||l|l|l||}
\hline \multirow{2}{*}{ Cases } & Monosomy7(-7) & 7q deletion(-7q31) & Both \\
\cline { 2 - 4 } & Frequency & Frequency & Frequency \\
\hline \hline AML (20) & $3 / 2015 \%$ & $2 / 20 \quad 10 \%$ & $3 / 2015 \%$ \\
\hline MDS (10) & $3 / 10 \quad 30 \%$ & $0 / 10 \quad 0 \%$ & $0 / 10 \quad 0 \%$ \\
\hline
\end{tabular}

Fig 4: FISH for chromosome 7 showing three signals: 2 green (internal control) and 1 red signal representing deletion of $7 q 31(-7 q)$

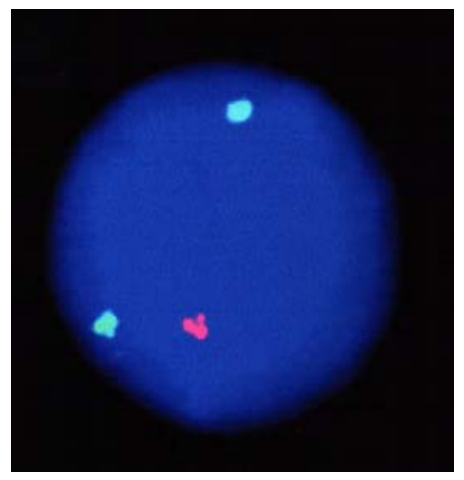

Fig 5: FISH for chromosome 7 showing two signals: 1 green and 1 red signal representing monosomy for chromosome 7 (-7)

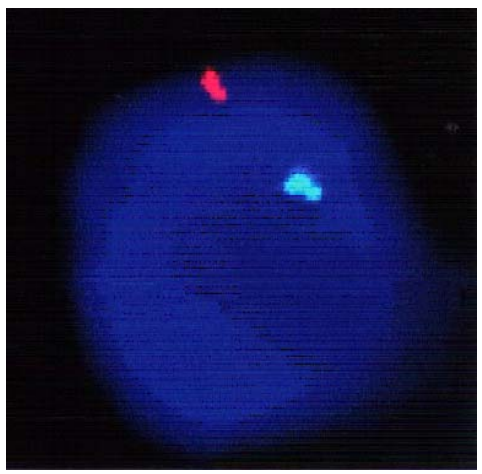

\section{Association between the clinical,} hematological data and the cytogenetic study A higher predominance of females; 9 females versus 2 males, was found in patients with chromosome 7 anomaly and the difference was statistically significant $(\mathrm{P}=0.02)$. The anomalies were also associated with splenomegaly and lymphadenopathy (P-value 0.034 and 0.043 respectively). Moreover, patients with Chromosome 7 abnormality showed a significantly higher mean TLC and PB blast cell counts $(\mathrm{P}=0.03$ and 0.01 respectively). Of the 8 AML cases showing chromosome 7 abnormality, 3/6 (50\%) cases were M4 phenotype, $3 / 4(75 \%)$ cases were M5 phenotype while $1 / 4(25 \%)$ case was M1 and $1 / 3(33 \%)$ case was M2. While the 3 monosomic 
MDS cases were Refractory anemia with excess blasts (RAEB) (none was refractory anemia [RA]). However there was no significant association between the type of leukemia and the chromosomal abnormality (data not shown).

Association between the clinical oqutcome and the cytogenetic study

Patients were followed up for a period of one year, 6 patients entered in complete remission (CR), (BM. samples were morphologically and immunophenotypically normal). MDS patients who turned to AML and AML patients who relapsed or failed to enter in complete remission were considered non responders to therapy (NR), these were 17 patients [21]. Patients who died due to relapse, organ failure or therapy related mortality were considered "Died", and they were 7 patients.

Patients who had normal FISH results showed a higher percentage of complete remission CR while patients with monosomy or deletion had higher rates of death or showed no response to therapy $(\mathrm{NR})(\mathrm{p}=0.03)($ Fig6)

Fig 6: Association between outcome and presence of anomaly

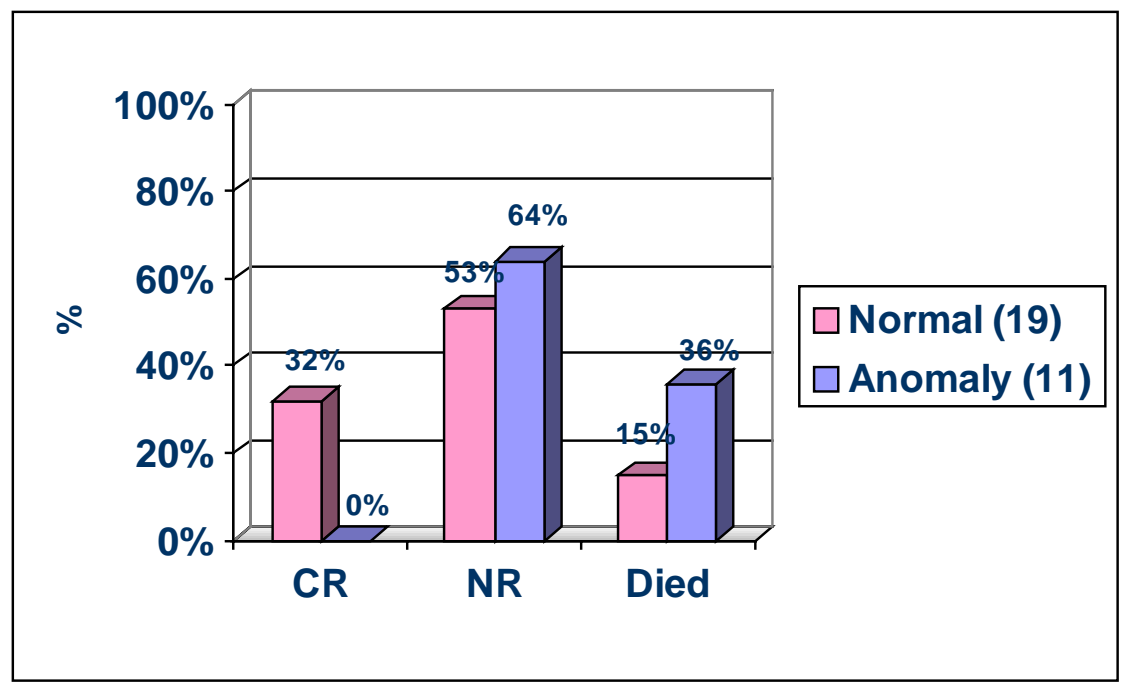

CR: complete remission

NR: No response to therapy

FISH results were also interpreted quantitatively; the number of positive nuclei was counted. These results also revealed a worse prognosis towards those who had a higher percentage of the genetic abnormality and the p-value was 0.027 (Table 3).

Table 3: Association between outcome and quantitative FISH results

\begin{tabular}{||l||l|l|l|l||}
\hline \hline Prognosis & N & $\begin{array}{l}\text { Quantit. FISH mean \% } \\
\pm \text { S.D. }\end{array}$ & p-value & Significance \\
\hline CR & $6(20 \%)$ & $0.83 \pm 1.60$ & $\mathbf{0 . 0 2 7}$ & Significant \\
\hline Died or NR & $24(80 \%)$ & $3.12 \pm 3.36$ & \\
\hline \hline
\end{tabular}

Table 4: Comparison between outcome of AML and MDS cases

\begin{tabular}{||l||l|l||l|l||}
\hline \hline \multirow{2}{*}{ Outcome } & Diagnosis & p-value & Significance \\
\cline { 2 - 3 } & MDS & AML & \multirow{2}{*}{$\mathbf{0 . 0 3}$} & \\
\hline CR(6) & $2(33 \%)$ & $4(67 \%)$ & & Significant \\
\hline NR(17) & $8(47)$ & $9(53 \%)$ & & \\
\hline Died(7) & & $7(100 \%)$ & \\
\hline
\end{tabular}

\section{Comparison between AML and MDS:}

On comparing AML with MDS cases regarding the outcome, AML patients had a worse outcome $(\mathrm{P}=$
0.03) (Table 4). Comparison between MDS and AML patients with the anomalies was not done due to the low number of MDS patients having 
chromosome 7 anomaly (3 cases) and they were all monosomic.

\section{Discussion}

The association between losses in the $7 \mathrm{q}$ region and the appearance of myeloid leukemia suggests that this region contains tumor suppressor gene(s) whose loss of function contributes to leukemia transformation or tumor progression but definitive evidence for their role has not been yet established. $[11,24]$. The complexity of $7 q$ rearrangements suggests that a synergy of different genetic factors, rather than the alteration of a single tumor suppressor gene, could be involved in the pathogenesis of del (7q) in myeloid disorders [25]. On the basis of cytogenetic and molecular methods, several critical regions in $7 q$ have been identified in chromosome bands: 7q22, 7q31.1, 7q32, 7q33-34 and $7 \mathrm{q} 35-36$ [26].

Aberrations of chromosome 7 are usually difficult to determine because of the heterogeneity of breakpoints and their occurrence in complex karyotypes, which are difficult to analyze cytogenetically. Complex karyotypes with multiple unbalanced translocations are observed in most cases of AML with -7/7q- . Thus, in many cases, fluorescent in situ hybridization (FISH) analysis may be helpful in revealing the involvement of this chromosome in structural aberrations. Taking into consideration the sensitivity of this technique, it can also confirm the numerical aberrations of chromosome 7, even when they occur in small populations of cells. Since $-7 / 7 \mathrm{q}$ - aberrations are considered as a poor prognostic factor in malignant myeloid disorders, establishing their presence is very important from the clinical point of view [27]. Thus, the aim of the present work was to detect the molecular abnormalities of chromosome 7 (monosomy 7 and $7 \mathrm{q} \mathrm{del},-7 / 7 \mathrm{q}-$ ) in MDS and AML patients using the FISH technique and whether it has an implication on the prognosis of these diseases.

Abnormalities of Chromosome 7 were found in $40 \%$ of patients in Group A and $33 \%$ of patients of Group B. However, the AML group (Group A) revealed both abnormalities, -7/7q- while monosomy 7 (-7) was the only abnormality found in Group B. Similar frequencies were observed by Brozek et al [9] and Chang et al. [28], the latter studied chromosomal abnormalities in 52 primary MDS patients in which abnormalities involving chromosome 7 was the most frequent cytogenetic abnormality and was found in $31 \%$ of cases. These were higher than previously observed by other authors, who detected -7/7q- in $12 \%, 8 \%, 9 \%$, $7.8 \%$ of AML patients respectively $[29,30,31,32]$. Others revealed monosomy 7 in $8 \%$ and $7 q-$ in $5 \%$ of AML cases [33].
Most of our cells failed to enter in metaphase and the count was carried on interphase cells yielding this relatively high frequency of Chromosome 7 aberrations which according to Brizard et al [34] would have given a lower percentage if metaphase cells were studied. This may also yield discrepancies between results of interphase FISH and conventional cytogenetics (CC) carried on metaphase spreads as detected by Kadam et al [35]. They explained that the aberrant clone are in G0 at the time of examination by $\mathrm{CC}$ or the inability to enter mitosis in vitro thereby passing undetected by metaphase examination [36]. They concluded that certain chromosomal aberrations e.g. those involving chromosome 7 are underestimated by Gbanding as a result of 2 factors: a) some cells do not proliferate in culture and hence cannot be karyotyped and b) others give rise to poor morphology metaphases which are excluded from the scoring.

Direct evidence for three distinct segments of chromosomal loss in the bands 7q22-31 have been identified [26]. Liang et al [37] found that more than $80 \%$ of their AML cases revealed allele loss for the entire region, a rare case of the $7 q$ chromosome showed allele loss for only the proximal 7q31.1 loci flanked by the markers D7S486 and D7S2456. Also, one of their cases with monosomy 7 revealed allele loss for loci at both $7 q 31$ and $7 q 22$ with retention of sequences between these sets of loci. Furthermore, a case of AML with no cytogenetic anomaly of chromosome 7 revealed a submicroscopic allelic imbalance for a third distal locus, D7S677. These findings suggest the presence of three distinct critical loci that may contribute alone or in combination to the evolution of MDS and AML. The data also provide molecular evidence for unbalanced translocation with noncontiguous deletions, as an alternate mechanism underlying monosomy 7 . This may also suggest that some of our patients may have had abnormalities in chromosome 7 outside $7 q 31$ with intact chromosome 7 centromere, thus giving false normal results which reflects an underestimation of the frequency of the anomaly

Monosomy of chromosome 7 was detected in 6 of our patients (3MDS and 3AML) with a mean FISH positivity of $17.3 \%$ and $7 \mathrm{q}$ deletion was detected in 2 cases (AML) with a mean positivity of $11 \%$ while both monosomy and deletion were detected in 3 cases of the whole studied group as shown in Table 2. These 3 cases were 2 males and 1 female, 2 of which had splenomegaly, hepatomegaly and lymphadenopathy. All of them had monocytic leukemias and none showed CR (2 of them died and 1 showed NR). There was a significant association between the presence of splenomegaly, lymphadenopathy, high TLC and peripheral blood (PB) Blast cell count with the 
presence of genetic anomaly, indicating the poor prognostic nature of chromosome 7 anomalies [38]

Aneuploidy of chromosome 7 was more frequently or the sole abnormality encountered in our MDS cases especially in the refractory anemia with excess blasts (RAEB) FAB subtype. Chromosome 7 aberrations were not encountered in M3 FAB subtype cases, in contrast to M4 and M5 cases in which they were frequently encountered. This may be attributed to the less favorable prognosis of M5 with extramedullary infiltration; gum infiltration and CNS disease [39].

Patients who had normal FISH results (19 patients) showed a higher percentage $(31.6 \%)$ of complete remission (CR) versus $0 \%$ in patients with monosomy or deletion (11 patients) who never entered in CR (100\%) and either died or showed no response to therapy (NR). Similar data were reported by other authors $[9,11]$. In the study by Brozek et al only $21 \%$ of patients with these abnormalities reached complete remission, showing a bad prognosis and poor response to therapy in the group of $-7 / 7 q-$ patients [9]. Quantitative FISH results also revealed a worse prognosis towards those who had a higher percentage of genetic abnormality.

AML patients had a worse outcome when compared to MDS patients. This is obvious from the pathogenesis of both diseases where in AML the normal marrow elements are replaced sometimes totally by the malignant blasts, whereas in MDS, there is insufficient differentiation capacity of the progenitors to mature blood cells [40]. Clinically, malignant myeloid disorders exhibiting -7/7q- have been associated with bad prognosis with high susceptibility to infections, poor response to chemotherapy, and short survival times $[11,41]$.

Studies demonstrated that FISH provides a rapid, quantitative method for the detection of cells with chromosome abnormalities in peripheral blood and bone marrow specimens. FISH could detect MRD in specimens that seemed normal by all standard morphological and cytogenetic criteria. Since FISH can be applied to interphase cells, results can be representative of the entire populations rather than restricted to cycling cells as is the case with routine cytogenetic analysis. Furthermore, the hybridization time will allow pretreatment investigations and disease monitoring to be performed directly on bone marrow smears with results available on the day of specimen collection. Also, the small amount of material required for FISH examination is particularly useful in hypocellular marrows and when aspiration is difficult [42]. Chromosome 7 abnormalities are heterogenous and some are part of unexpected complex rearrangements often impossible to detect or interpret correctly without using FISH techniques. Also, deletions may be accompanied by translocations which are identifiable only by FISH [43].

Diagnostic accuracy in acute leukemias can be improved if traditional morphology and cytochemsitry are supplemented with immunophenotyping and genotypic analysis. This multiparameter approach is of crucial importance for the management of patients as it enables the identification of leukemic syndromes with distinct biological features and response to treatment. Cytogenetic findings can be quite helpful in establishing the correct diagnosis and can add information of prognostic significance [44]. They help in the diagnosis, prognosis, monitoring and therapy decisions [32].

\section{Conclusion}

While FISH will not replace routine karyotypic analysis of material at presentation, it does provide a powerful and sensitive tool for monitoring the disease in patients with karyotypic abnormalities. Thus the detection of chromosome 7 abnormalities by FISH is very important since this chromosome harbors tumor suppressor genes so this allows better understanding of the mechanism of leukemogenesis and the molecular categorization of these diseases for better stratification of treatment modalities.

\section{References}

1. Chen Z, Pasquini M, Hong B, Dehart S, Heikens M, Tsai S. The human Penumbra gene is mapped to a region on chromosome 7 frequently deleted in myeloid malignancies. Cancer Genetics and Cytogenetics. 2005; 162: 95-98

2. Liang H, Fairman J, Claxton DF, Nowell PC, Green ED and Nagarajan L. Molecular anatomy of chromosome $7 \mathrm{q}$ deletions in myeloid neoplasms: evidence for multiple critical loci. Proceedings of the National Academy of Science, USA. 1998; 95:3781-5.

3. Le Beau MM, Espinosa R 3rd, Davis EM, Eisenbart JD, Larson RA and Green ED. Cytogenetic and molecular delineation of a region of chromosome 7 commonly deleted in malignant myeloid diseases. Blood. 1996; 88: $1930-5$.

4. Pedersen B and Ellegaard J. A factor encoded by $7 q 31$ suppresses expansion of the $7 q$-clone and delays, cytogenetic progression. Cancer Genetics and Cytogenetic. 1994; 78:181-8.

5. Velloso ER, Michaux L, Ferrant A, Hernandez JM, Meeus P, Dierlamm J, Criel A, Louwagie A, Verhoef $\mathrm{G}$, Boogaerts $\mathrm{M}$, Michaux JL, 
Bosly A, Mecucci C and Van den Berghe $\mathrm{H}$. Deletions of the long arm of chromosome 7 in myeloid disorders: loss of band 7q32 implies worst prognosis. British Journal of Haematology. 1996; 92:574-81.

6. Aquino M, Schneider NR and Sandler ES. Secondary myelodysplasia with monosomy 7 arising after treatment for Acute Lymphoblastic Leukemia in childhood. Journal of Pediatriatic Hematology and Oncology. 2001; 23:48-50.

7. Trobaugh-Lotrario AD, Kletzel M, Quinones RR, McGavran L, Proytcheva MA, Hunger SP,

Malcolm J, Schissel D, Hild E, Giller RH. Monosomy 7 associated with pediatric AML and MDS: successful management by allogenic hematopoietic stem cell transplant. Bone Marrow Transplant, 2005; 35:143-149.

8. Jaeger U and Kainz B. Monitoring of MRD in AML: the right type for real time-PCR. Annals of Hematology. 2003; 82:139-47

9. Brozek I, Babinska M, Kardas I, Wozniak A Balcerska A, Hellmann A and Limon J. Cytogenetic analysis and clinical significance of chromosome 7 aberrations in acute leukemia. Journal of Applied Genetics. 2003; 44: 401-412

10. Koike M, Takeuchi S, Yokota J, Park S, Hatta, Y, Miller,CW, Suruoka, N and Koeffler HP. Frequent loss of heterozygosity in the region of the D7S523 locus in advanced ovarian cancer. Genes Chromosomes Cancer. 1997; 19:1-5.

11. Basirico R, Pirrotta R , Fabbiano F , Mirto S , Cascio L , Pagano M , Cammarata G , Magrin $\mathrm{S}$ and Santoro A. Submicroscopic deletions in the $7 \mathrm{q}$ region are associated with recurrent chromosome abnormalities in acute leukemia. Haematologica. 2003; 88:429-437.

12. Vanni R, Marras S, Schoenmakers, EF, Dal Cin P, Kazmierczak B, Senger, G, Bullerdiek ., Van de Ven,WJM and Van den Berghe H. Molecular cytogenetic characterization of $\operatorname{del}(7 q)$ in two uterine leiomyoma-derived cell lines. Genes Chromosomes Cancer. 1997; 18:155-161.

13. Hernandez JM, Schoenmakers EFPM, Dal Cin P, Michaux L, Van de Ven WJM and Van den Berghe H. Molecular delineation of the commonly deleted segment in mature B-cell lymphoid neoplasias with deletion of $7 \mathrm{q}$. Genes Chromosomes Cancer. 1997; 18:147150.

14. Fischer K, Frohling S, Scherer SW, Brown J M, Scholl C, Stilgenbauer S, Tsui LC, Lichter, $\mathrm{P}$ and Dohner H. Molecular Cytogenetic Delineation of Deletions and Translocations Involving Chromosome Band 7q22 in Myeloid Leukemias. Blood. 1997; 89:2036-2041.
15. Le Beau MM, Espinosa R. III, Davis EM, Eisenbart JD, Larson RA and Green ED. Childhood monosomy 7: epidemiology, biology, and mechanistic implications. Blood. 1997; 88:1930-1935.

16. Todd R, Bia B, Johnson E, Jones C and Cotter F. Molecular characterization of a myelodysplasia-associated chromosome 7 inversion. British Journal of Hematology. 2001; 113:143-152.

17. Bennett JM, Catovsky D, Daniel MT, Flandrin G. and Sltan C. Proposals for the classification of MDS. British Journal of Hematology. 1982; 51: 189-92.

18. Bennett JM, Catovsky DS and Daniel MT. Criteria for the diagnosis of acute leukemia of megakaryocytic linage (M7). Annals of Internal Medicine. 1985; 103: 460-66.

19. Chang H, Salma F, Yi QL, Patterson B, Brien $B$ and Minden MD. Prognostic relevance of immunophenotyping in 379 patients with AML. Leukemia Research. 2004; 28:43-48.

20. Neben K, Schnittger S, Brors B, Tews B, Kokocinski F, Haferlach T, Muller J, Hahn M, Hiddemann W, Eils R, Lichter P and Schoch C. Distinct gene expression pattern associated with FLC111 and NRAS activating mutation in AML with normal karyotype. Oncogenetics. 2005; 24:1580-8.

21. Olney HJ and le Beau MM. The cytogenetics of myelodysplastic syndrome. Best practice and research. Clinical Hematology. 2001; 14: 479-95

22. Flactif M, Lai JL, Preudhomme $\mathrm{C}$ and Fenaux P. Fluorescence in situ hybridization improves the detection of monosomy 7 in MDS. Leukemia. 1994: 8:1012-18.

23. Brizard F, Brizard A, Guilfort F, Tanzer J and Berger R. Detection of monosmy 7 and trisomies 8 and 11 in myelodysplastic disorders by interphase FISH. Comparison with acute lymphocytic leukemias. Leukemia. 1994; 8:1005-1011

24. Ebert BL and Golub TR. Genomic approaches to hematologic malignancies. Blood. 2004; 104: 923-932.

25. Gonzalez MB, Gutierrez NC, Garcia JL and Schoenmakers EF. Heterogeneity of structural abnormalities in the $7 q 31.3$ approximately q34 region in myeloid malignancies. Cancer Genetics and Cytogenetic. 2004; 150:136-43

26. Hofmann WK and Koeffler HP. Myelodysplastic syndrome. Annual Review of Medicine. 2005; 18;56:1-16.

27. Haferlach T, Kern W, Schoch C and Schnittger S. A new prognostic score for patients with AML based on cytogenetics and early blast clearance in trials of the German AML Cooperative Group. Hematologica. 2004; 89: 408-18. 
28. Chang KL, O'Donnell MR, Slovak ML and Dagis AC, Arber DA, Niland JC, Forman SJ. Primary myelodysplasia occurring in adults under 50 years old. A clinicopathologic study of 52 patients. Leukemia. 2002; 16:623-631.

29. Perkins D, Brennan S, Carstairs K and Bailey D. Regional cancer cytogenetics: A report on 1,143 diagnostic cases. Cancer Genetics and Cytogenetic. 1997; 96: 64-80.

30. Mauritzson N., Johansson B., Albin M. and Billstrom R. A single-center population-based consecutive series of 1500 cytogenetically investigated adult hematological malignancies: karyotypic features in relation to morphology, age and gender. European Journal of Haematology. 1999; 62: 95-102.

31. Slovak M.L., Kopecky K.J., Cassileth P.A. and Harrington D.H. Karyotypic analysis predicts outcome of pre-remission and post-remission therapy in adult acute myeloid leukemia: a southwest Oncology Group/Eastern Cooperative Oncology Group study. Blood. 2000; 96: 4075-83.

32. Byrd JC, Mrozek K, Dodge RK, Carroll AJ, Edwards CG, Arthur DC, Pattenati MJ, Patil SR. Pretreatment cytogenetic abnormalities are predictive of induction success, cumulative incidence of relapse and overall survival in adult patients with de novo acute myeloid leukemia: results from cancer and leukemia Group B (CALGB 8461). Blood. 2002; 100:4325-36.

33. Grimwade D, Walker H, Harrison $G$ and Oliver F. The predictive value of hierarchical cytogenetic classification in older adults AML: analysis of 1065 patients entered into the United Kingdom Medical Research Council AML 11 trial. Blood. 2001; 98:1312-20.

34. Schoch C, Schnittger S, Burch S and Gerstner D. Comparison of chromosome banding analysis, interphase-and hypermetaphaseFISH, qualitative \& quantitative PCR for diagnosis \& for follow up in CML, a study on 350 cases. Leukemia. 2002; 16:53-59.

35. Kadam P., Umerani A., Raza A. et al. Combination of classical and interphase cytogenetics to investigate the biology of myeloid disorders: detection of masked monosomy 7 in acute myeloid leukemia. Leukemia Research. 1993; 17:365-374.

36. Tanaka K, Arif M, Eguchi M, Shintani T, Kumaravel TS, Asaoku H, Kyo T, Dohy H, and Kamada N. Interphase FISH overcomes pitfalls of $\mathrm{G}$ banding analysis with special references to underestimation of chromosomal aberration rates. Cancer Genetics and Cytogenetic. 1999: 115: 32-38.
37. Liang H, Fairman J, Claxton DF, Nowell PC, Green ED and Nagarajan L. Molecular anatomy of chromosome $7 \mathrm{q}$ deletions in myeloid neoplasms: Evidence for multiple critical loci. Proceedings of the National Academy of Science USA. 1998;95 37813785.

38. Pulsoni A, Pagano L, Latagliata R, Casini M, Cerri R, Crugnola M, De Paoli L, Di Bona E, Invernizzi R, Marmont F, Petti MC, Rigolin G, Ronco F, Spadano A, Tosti E, Visani G, Mele A and Mandelli F. Survival of elderly patients with acute myeloid leukemia. Haematologica. 2004; 89: 296-302.

39. Hoffbrand AV, Pettit JE and Moss PA. Acute leukemia and MDS. Essential hematology $4^{\text {th }}$ edition by Hoffbrand A.V. Pettit, J.E., Moss, P.A.H. (eds) Blackwell Science Ltd. 2001; pp163-90.

40. Matsuo T, Kuriyama K, Miyazaki Y, Yoshida S, Tomonaga M, Emi N, Kobayashi T, Miyawaki S, Matsushima T, Shinagawa K, Honda S, and Ohno R. Japan Adult Leukemia Study Group. The percentage of myeloperoxidase-positive blast cells is a strong independent prognostic factor in acute myeloid leukemia, even in the patients with normal karyotypes. Leukemia. 2003; 17: 1538-43.

41. Martinez-Ramirez A, Urioste M, Melchor L, Blesa D, Valle L, de Andres SA, Kok K, Calasanz MJ, Cigudosa JC, Benitez J. Analysis of myelodysplastic syndromes with complex karyotypes by high-resolution comparative genomic hybridization and subtelomeric CGH array. Genes Chromosomes and Cancer. 2005; 42:287-98.

42. Schoch C, Schnittger S, Bursch S, Gerstner D, Hochhaus A, Berger U, Hehlmann R, Hiddemann $\mathrm{W}$ and Haferlach T. Comparison of chromosome banding analysis, interphaseand hypermetaphase-FISH, qualitative \& quantitative PCR for diagnosis \& for follow up in CML, a study on 350 cases. Leukemia. 2002; 16:53-59.

43. Brown J, Jawad M, Twigg SR, Saracoglu K, Sauerbrey A, Thomas AE, Eils R, Harbott J, Kearney L.A cryptic $\mathrm{t}(5-11)(\mathrm{q} 35, \mathrm{p} 15.5)$ in 2 children with acute myeloid leukemia with apparently normal karyotypes, identified by a multiplex fluorescence in situ hybridization telomere assay. Blood. 2002; 99: 2526-2531.

44. VinSheth FJ, Sheth JJ, Patel AI,Shah AD and Verhest A. Usefulness of cytogenetics in leukemias. Indian Journal of Cancer. 2002; 39:139-142 